\title{
Economia Solidária, Etnomatemática e Andragogia no contexto de um Banco Comunitário ${ }^{13}$
}

\section{Renata Cristina GeromelMeneghetti \\ Douglas Felipe Giaquinto}

\section{Resumo}

Este artigo refere-se à continuação de um trabalho em Educação Matemática no contexto de um Banco Comunitário (BC), caracterizado como um Empreendimento Econômico Solidário (EES), e tem por finalidade abordar o processo de ensino e aprendizagem de matemática de forma contextualizada, visando atender as demandas específicas de conhecimentos matemáticos inerentes às atividades do BC. As intervenções em Educação Matemática focalizadas neste trabalho ocorreram considerando os pressupostos teóricos da Economia Solidária, da Andragogia e da Etnomatemática, concomitantemente. Tais intervenções foram realizadas mediante situações-problema envolvendo análise da viabilidade da implantação de dois novos EES fictícios propostos pelo grupo e envolveram conceitos matemática inerentes ao levantamento dos custos fixos, custos variáveis, custo dos materiais necessários para produção do produto, processo de precificação do produto e capital de giro necessário. A metodologia de investigação segue uma abordagem qualitativa, em que se aborda nossa atuação em Educação Matemática junto ao referido banco. Como resultado, percebeu-se que as intervenções têm possibilitado aos membros do BC a aquisição e compreensão dos conhecimentos matemáticos de que necessitam de maneira mais significativa ao grupo; implicando na obtenção de uma autonomia maior nas atividades desenvolvidas junto ao banco e à comunidade. Assim, este trabalho reforça nossa percepção de que a Educação Matemática pode auxiliar o sujeito na transformação e na construção de uma nova realidade tanto no âmbito do trabalho quanto da vida em comunidade.

Palavras-chave: Etnomatemática; Andragogia; Economia Solidária; Ensino e Aprendizagem de Matemática.

\footnotetext{
13 Uma versão preliminar e parcial deste trabalho foi publicada nos anais do XII ENEM (Encontro Nacional de Educação Matemática). Evento promovido pela Sociedade Brasileira de Educação Matemática e realizado na Universidade Cruzeiro do Sul, de 13 a 16 de julho de 2016, São Paulo.
} 


\section{Solidarity Economy, Ethnomathematics and Androgogyin the context of a Community Bank}

Renata Cristina GeromelMeneghetti

Douglas Felipe Giaquinto

\section{Abstract}

This article continues the research on Mathematics Education in the context of a Community Bank (BC), characterized as an Enterprise in Solidarity Economy (ESE). It addresses the process of teaching and learning Mathematics in a contextualized way for attending the specific demands of mathematical knowledge inherent to the $\mathrm{BC}$ activities.The interventions in Mathematics Education focused considered the theoretical assumptions of the Solidarity Economy, Andragogy and Etnomathematic concurrently and occurred through problems involving analysis of the viability of the implantation of two new fictive ESE proposed by the group. They also comprehended mathematical concepts inherent to fixed and variable costs, costs of materials for the manufacture of the product, the product-pricing process and working capital required.The methodology followed a qualitative approach and focused on our performance in Mathematics Education at the above-mentioned bank. The interventions enabled $\mathrm{BC}$ members to acquire and understand the necessary mathematical knowledge in a more meaningful way and the obtaining of greater autonomy in the bank and community activities. Our perception Mathematics Education can help individuals to transform and construct a new reality in both work and community life scopes has been reinforced.

Keywords: Ethnomathematics; Andragogy; Solidarity Economy; Teaching and Learning Mathematics. 


\section{Introdução}

Este trabalho é parte de um projeto de Educação Matemática no contexto da Economia Solidária (ES) e se dá em parceria com o NUMI-EcoSol/UFSCar (Núcleo Multidisciplinar e Integrado de Estudos, Formação e Intervenção em Economia Solidária da Universidade Federal de São Carlos/SP) ${ }^{14}$, responsável pela inserção e acompanhamento de Empreendimentos Econômicos Solidários (EES).

Assim, objetivou-se, neste trabalho, dar continuidade a uma pesquisa de Educação Matemática no contexto de um Banco Comunitário (BC), a qual aborda o processo de ensino e aprendizagem de matemática de forma contextualizada focando novos conteúdos, como, por exemplo, porcentagem e regra de três, que visava sanar as dificuldades específicas de conhecimentos matemáticos das colaboradoras do BC para a melhoria da capacidade de articulação desses conteúdos com as atividades financeiras do banco.

O BC é um EES que se situa em um bairro periférico de uma cidade do interior do Estado de São Paulo. Ele foi implementado através de um Projeto de Finanças Solidárias com Base nos Bancos Comunitários, com apoio da Secretaria Nacional de Economia Solidária e do Ministério do Trabalho e Emprego, e executado pelo NESOL-USP (Núcleo de Economia Solidária da Universidade de São Paulo) ${ }^{15}$ e pelo NUMI-Ecosol/UFSCar, como condição para o desenvolvimento territorial/social/econômico deste bairro e de seu entorno, por meio da ampliação do acesso de seus moradores a serviços financeiros solidários de baixo custo.

Trata-se de uma organização sem fins lucrativos que oferece serviços financeiros solidários à comunidade carente e cujo papel principal é estimular a geração de trabalho e renda da mesma, fazendo com que estes serviços sejam, além de mais acessíveis, também um instrumento de organização e estímulo ao desenvolvimento local. O banco possui duas linhas de crédito, a saber, o crédito de consumo (concedido em moeda social sem juros) e o crédito produtivo (concedido em reais ou em moeda social com uma taxa de $1 \%$ de juros simples ao mês). O crédito de consumo é concedido para membros da comunidade e o produtivo é concedido para EES (novo ou já existente) dessa mesma comunidade.

A importância da circulação da moeda social dentro do território vai além da divulgação do $\mathrm{BC}$, pois permite que se criem laços entre moradores e comerciantes para fomentar o desenvolvimento político/social/econômico do próprio território e de seu entorno. Contudo, os EES só existem graças a ES, a qual tem por objetivo criar atividades econômicas sustentáveis, geridas na base da cooperação, visando tanto o desenvolvimento territorial, quanto a construção de outras relações sociais, tais como: cooperativismo, companheirismo e afeto entre os membros. A ES se tornou uma alternativa de geração de

14http://www.numiecosol.ufscar.br/numi-ecosol

15 http://www.itcp.usp.br/ 
trabalho e renda impactando na inclusão social desse empreendimento e de outros, a saber, cooperativas, associações, feiras de troca, empresas autogestionárias, entre outras.

O trabalho de Educação Matemática com esse banco teve início em 2013 e o artigo de Meneghetti e Barrafoldi (2015) traz resultados sobre as intervenções anteriores realizadas junto aos membros do BC. Tais atuações ocorreram por meio de situações-problema contextualizadas e focalizaram conteúdos de matemática considerados básicos para as atividades junto a este empreendimento, a saber: porcentagem, razão e proporção, regra de três e operações básicas envolvendo números racionais.

Em relação a essa fase anterior da pesquisa, as autoras destacaram que houve melhoras significativas, principalmente quanto à organização do raciocínio matemático; a realização de algumas operações básicas: divisão e multiplicação envolvendo números decimais; a utilização correta da calculadora e ressignificação dos números mostrados no visor da calculadora; compreensão de cálculos proporcionais necessários na planilha de análise e controle de crédito produtivo.

As atuações junto a esse EES ainda continuam, já que nem todos os conteúdos de matemática necessários a este grupo foram suficientemente trabalhados e, além disso, houve a integração de um novo membro junto a esse EES, o que implicou em se realizar novos diagnósticos considerando a especificidade de cada pessoa.

Neste trabalho, focalizaremos as intervenções realizadas durante o período de setembro de 2015 a maio de 2016, que tiveram, num primeiro momento, o objetivo de fortalecer conceitos básicos de matemática, pois notou-se que uma das maiores dificuldades dos membros dos EES decorre do medo e/ou da falta de embasamento que eles têm ao lidarem com conhecimentos matemáticos. Para tal, foram utilizadas situações-problema contextualizadas envolvendo a viabilidade da implantação de empreendimentos fictícios e focalizaram-se conceitos inerentes ao levantamento dos gastos (custos fixos, variáveis, custo do material para produção do produto) a fim de se chegar a uma proposta de preço para a venda do produto. Esse processo se deu de forma acessível e de maneira que as colaboradoras pudessem associar os dados à realidade do BC.

Num segundo momento, tivemos como propósito desenvolver, junto às integrantes do BC, uma análise a respeito da viabilidade da implantação de um EES de produção de pães caseiros sugerido por elas mesmas e, a partir disso, trabalhar conteúdos de matemática básica visando auxiliá-las no processo de precificação e na análise de vários fatores, foram eles: produção mensal e capital de giro, a se considerar quando da criação de um novo EES.

\section{O Banco Comunitário}

O BC é uma associação de autogestão, gerida por pessoas da própria comunidade. Sobretudo, todo trabalho desenvolvido dentro do banco tem como foco principal contribuir 
para o desenvolvimento local. Contudo, é de suma importância que as colaboradoras (ou seja, as integrantes deste banco) tenham um domínio básico de matemática financeira, pois o objetivo é que futuramente possam analisar a viabilidade de um empreendimento e lidar com as burocracias financeiras que surgem de empréstimos.

Sendo assim, entendemos que a Educação Matemática tem um papel fundamental na construção de uma aprendizagem mais significativa. Tal abordagem leva em consideração os conhecimentos adquiridos ao longo da vida dessas pessoas para que a aprendizagem se dê de forma contextualizada às suas realidades, levando a uma reflexão que traga sentido ao que é feito neste contexto.

As intervenções em Educação Matemática focalizadas neste trabalho ocorreram considerando os pressupostos teóricos da ES, da Androgogia e da Etnomatemática, concomitantemente. No que segue, apresentaremos os princípios desses pilares teóricos que embasaram este trabalho.

\section{Pressupostos teóricos, Economia Solidária (ES)}

A ES é uma nova forma de economia alternativa ao capitalismo e que se desenvolveu de acordo com as necessidades da população a fim de promover a (re)inclusão social por meio da articulação de movimentos sociais e empreendimentos econômicos solidários. Seus princípios gerais são: a valorização social do trabalho humano, satisfação plena da necessidade de todos (como elemento principal da criatividade tecnológica e da atividade econômica), busca de uma relação de troca respeitosa com a natureza e o direito à liberdade individual (SINGER, 2000).

De acordo com Singer (2002), a ES possui as seguintes características: Cooperação: existência de interesses e objetivos comuns, a união de esforços e capacidades; Autogestão: os participantes das organizações exercitam as práticas participativas de autogestão dos processos de trabalho sem que apoios externos substituam o protagonismo dos sujeitos agentes; DimensãoEconômica: envolve o conjunto de elementos de viabilidade econômica, permeados por critérios de eficácia e efetividade, ao lado dos aspectos culturais, ambientais e sociais; Solidariedade: o caráter de solidariedade nos empreendimentos é expresso em diferentes dimensões: distribuição dos resultados, oportunidades para desenvolvimento, compromisso com o meio ambiente, relações sociais, participação em ações sustentáveis, relação com movimentos sociais emancipatórios, preocupação com o bem-estar, respeito aos direitos dos trabalhadores.

Ainda segundo Singer (2002), a ES é um modo de produção cuja característica central é a igualdade de direitos, acrescida da autogestão. Neste tipo de economia, os empreendimentos são geridos pelos próprios trabalhadores coletivamente e de forma 
inteiramente democrática. Como mencionado no parágrafo acima, uma das principais características da ES é sua forma de gestão, pois nela emprega-se a autogestão.

Por autogestão, em sentido lato, entende-se o conjunto de práticas sociais que se caracteriza pela natureza democrática das tomadas de decisão, que propicia a autonomia de um "coletivo". É um exercício de poder compartilhado, que qualifica as relações sociais de cooperação entre pessoas e/ou grupos, independente do tipo das estruturas organizativas ou das atividades, por expressarem intencionalmente relações sociais mais horizontais. (ALBUQUERQUE, 2003, p. 20).

O modelo de organização baseado na autogestão prioriza a autonomia da organização do empreendimento, a valorização do ser humano e um processo democrático de tomada de decisões.

Em geral, os EES pautam suas ações nos princípios da ES. Esses empreendimentos, na sua forma mais comum, desenvolvem-se a partir de associações, cooperativas, empresas autogestionárias, grupos de produção, clubes de trocas, entre outros.

Muitas vezes, esses empreendimentos possuem dificuldade para se fixarem no mercado, principalmente pela concorrência, falta de conhecimento ou de estratégias financeiras e pela necessidade de se ter um capital de giro. Por isso, há necessidade de se considerar a viabilidade de implantação de um novo EES.

\section{Andragogia}

É importante ressaltar que as integrantes do BC estão fora da escola há muito tempo e que têm bagagens conceituais bem distintas. A partir disso, pensou-se em abordar o processo de aprendizagem com base no conhecimento que elas já possuíam. A priori, percebemos que o sujeito adulto necessita entender o valor e a utilidade de aprender determinados conceitos e deve ser deixado livre para direcionar seu próprio aprendizado. Além disso, é importante levar sempre em consideração o referencial conceitual que cada indivíduo possui. Em relação à matemática, é comum que existam dificuldades de aprendizagem de certos conceitos, o que pode estar relacionado à forma como a mesma foi abordada em situações de ensino.

A Matemática torna-se, muitas vezes, distante de seus significados e objetivos na Educação Básica, devido à maneira como é abordada e a ênfase dada somente à simbologia e não ao contexto, ou seja, ao fato de se apresentar como uma ciência isolada e que não está presente no cotidiano. (OGLIARI, 2008, p. 2).

No contexto de EES, os trabalhos de Meneghetti e Kucinskas (2014) apresentam dados a partir dos quais se observa que a Educação Formal muitas vezes se distancia da realidade dessas pessoas e de suas necessidades, em especial, aquelas referentes a seus cotidianos de trabalho. 
Levando isso em consideração, adotamos também em nossas intervenções os princípios da Andragogia, um novo conceito que propõe autonomia, colaboração e autogestão da aprendizagem. O termo Andragogia está relacionado à educação de adultos com aplicações em educação continuada e na graduação universitária (CAVALCANTI, 2005). Knowles et al. (200916 apud SHINODA et al., 2014) destacam os seguintes princípios da Andragogia: (1) a necessidade de conhecer: os adultos necessitam saber a utilidade e o valor do material que estão usando antes de se envolverem na aprendizagem; (2) autoconceito de indivíduo: o autoconceito do adulto aprendiz deve ser auto direcionado e autônomo; (3) o papel da experiência: as experiências prévias são o mais rico recurso disponível para o indivíduo que aprende; (4) prontidão para aprender: entre os adultos, a prontidão para aprender depende da valorização da relevância do tópico tratado e de como ele contribui para sua situação de vida e seus problemas; (5) orientação para a aprendizagem: a orientação dos adultos para aprender deve ser centrada no problema, na tarefa e na vida; o que os motiva é perceber que o conhecimento os ajudará a desempenhar tarefas e resolver problemas; (6) motivação: os adultos estão direcionados, principalmente, por pressão interna, pela motivação, pelo desejo de autoestima e pela meta realizada.

Nesse contexto, o aprendiz deve ser estimulado a trabalhar em grupos, a desenvolver suas próprias ideias, a refletir e a pensar de forma crítica sobre tudo que lhe é apresentado, a fim de potencializar o seu aprendizado que pode se dar por meio de estudo de casos, jogos virtuais, experiências reais, entre outros. Ademais, é preciso que conhecimentos e experiências sejam compartilhados, porque o aprendizado é uma troca, na qual todos ganham mais conhecimentos.

Além disso, em nossas intervenções, pautamo-nos também em alguns dos pressupostos teóricos da Etnomatemática, que serão apresentados a seguir.

\section{Etnomatemática}

A Etnomatemática enfatiza a compreensão da realidade no interior de um contexto cultural próprio. Nesse contexto, a matemática surge como resposta às pulsões de sobrevivência e de transcendência, que sintetizam a questão existencial da espécie humana (D’AMBROSIO, 2001).

De acordo com D’Ambrosio, a Etnomatemática é compreendida como a arte ou técnica de entender a realidade, dentro de um contexto cultural próprio. A cultura diz respeito a um conjunto de conhecimentos compartilhados e comportamentos compatibilizados sobre a realidade (matema) que se manifesta nas maneiras (ticas) próprias ao grupo, à comunidade (etno), isto é, na sua Etnomatemática (D’AMBROSIO, 1996; 2001).

${ }^{16}$ KNOWLES, M. S.; HOLTON III, E. F.; SWANSON, R. A. Aprendizagem de Resultados: uma abordagem prática para aumentar a efetividade da educação corporativa. Rio de Janeiro: Elsevier, 2009. 
A Etnomatemática permite entender o processo cognitivo numa relação dialética entre artefatos e mentefatos, isto é, entre códigos e símbolos, respectivamente, e, a partir disto, pode-se propor práticas educacionais. A aquisição do conhecimento se dá por meio de uma relação dialética entre o saber e o fazer, impulsionada pela consciência. A ação gera conhecimento, capacidade de explicar, de lidar, de manejar, de entender a realidade (D’AMBROSIO, 1996). No âmbito da Etnomatemática, tal como destaca o autor, a aprendizagem é compreendida como a capacidade de explicar, aprender, compreender e enfrentar de forma crítica novas situações.

D’Ambrosio (2005) enfatiza que a educação é responsável pela construção da cultura, pois transforma ou modifica o comportamento individual em social e, por sua vez, gera a cultura. Ele (Id., 2001) afirma que insistir em “Educação para Todos” só se justifica se for possível conseguir, por meio dela, melhorar a qualidade de vida e dar maior dignidade à humanidade como um todo.

Como enfatizado em Meneghetti (2013, p. 547), no âmbito da ES “[...] uma atuação pedagógica pode [...] ser respaldada na Etnomatemática ao se abordar a matemática de forma contextualizada e respeitando os interesses culturais e sociais do grupo". Tal como destacado por Moreira (2009), a matemática científica é entendia como ferramenta interativa para a matemática do cotidiano, na direção de se articular a matemática local com a global. Esta autora ainda salienta que para desenvolver uma Educação Matemática para todos, não basta apenas contextualizar o grupo social do aluno, temos que entender também a função de cada pessoa do grupo. As necessidades individuais são diferentes "[...] e, consequentemente, a resposta deve ser individualizada por parte da escola" (MOREIRA, 2009, p. 61).

Dessa maneira, considerando os pressupostos da Etnomatemática e da Andragogia, em nossas intervenções pedagógicas junto ao BC, procuramos entender e trabalhar conceitos matemáticos considerando o contexto cultural deste EES, partindo dos conhecimentos prévios de seus integrantes, identificados no cotidiano de trabalho deste grupo.

Assim, diante desse contexto, entendemos ser importante que conceitos matemáticos sejam apresentados de forma contextualizada às possíveis atividades do $\mathrm{BC}$ de maneira a facilitar o entendimento.

\section{Metodologia}

A metodologia de investigação baseia-se numa abordagem qualitativa, em que se focalizou a intervenção de Educação Matemática que realizamos junto ao BC, por isso aborda nossa intervenção no caso particular do $\mathrm{BC}$ e, portanto, identifica-se como uma pesquisa qualitativa que leva em consideração elementos de um estudo de caso (LÜDKE; ANDRÉ, 1986). Segundo essas autoras, este tipo de abordagem visa à descoberta, enfatiza a interpretação em contexto, busca relatar a realidade de forma completa e profunda; pode 
utilizar-se de várias fontes de informação e apresenta os dados por meio de uma linguagem mais acessível.

As intervenções em Educação Matemática focalizadas neste trabalho foram realizadas com os membros do BC durante três horas por semana com a participação de três integrantes, compreendendo o período de setembro de 2015 a maio de 2016; e com a participação de uma nova colaboradora no período de fevereiro a maio de 2016.

Os dados foram registrados em diário de campo do pesquisador (aqui designado pela letra P). As quatro integrantes do BC possuem graus de escolaridade diferentes: enquanto $\mathrm{A}, \mathrm{B}$ e $\mathrm{C}$ tinham concluído o ensino médio há bastante tempo, $\mathrm{D}$ precisou interromper os estudos quando cursava a quarta série do ensino primário.

As intervenções trataram de situações-problema para análise da viabilidade da implantação de dois novos EES (fictícios) propostos pelo grupo, e envolveram conceitos matemáticos inerentes ao levantamento dos custos fixos, custos variáveis, custo dos materiais necessários para produção do produto, processo de precificação do produto e capital de giro necessário.

\section{Desenvolvimento}

\section{Primeira Fase: situações-problema contextualizadas envolvendo empreendimento fictício de produção de sabão.}

Buscar uma valorização das formas de conhecer e interpretar a realidade dos diferentes grupos culturais, como sugerido pela Etnomatemática (D’AMBROSIO, 2001) tem sido essencial para o desenvolvimento das intervenções de Educação Matemática no contexto dos EES. Para as intervenções em Educação Matemática foi fundamental conhecer a realidade do $\mathrm{BC}$, bem como as especificidades de cada uma de suas colaboradoras. Nesse sentido, lançou-se a ideia de trabalhar a matemática por meio da análise de empreendimentos (podendo este ser fictício) que fossem semelhantes a algum dos já existentes no bairro onde residem as colaboradoras do $\mathrm{BC}$ e que fossem do conhecimento de todas.

O empreendimento escolhido para análise foi proposto pela colaboradora $\mathrm{C}$ que comentou já ter feito parte de uma cooperativa de sabão que, há uns anos fora viável, porém com o passar do tempo essa cooperativa se desintegrou e atualmente a colaboradora gerencia tal empreendimento sozinha. Com isso, ficou decidido que seria interessante analisar o processo de precificação de um dos produtos que a colaboradora $\mathrm{C}$ comercializa. Um levantamento foi feito com base nos preços atuais de tais produtos, bem como de todo o procedimento: desde o processo inicial (fabricação) até o processo final (comercialização).

Com base nos princípios da Andragogia e da Etnomatemática, o passo inicial deu-se a partir de um diálogo aberto com as colaboradoras a fim de discutir sobre a fabricação do 
sabão caseiro e sua real utilidade, visando uma possível geração de renda ou até mesmo para o próprio consumo. Por consequência, o diálogo propiciou uma reflexão natural por parte das colaboradoras que indagaram:

Colaboradora A: "A fabricação de sabão de soda é algo cultural na minha família, mas como sempre a minha sogra me doa alguns, então nunca precisei fazer".

Colaboradora B: "Nossa, bem que eu poderia fazer esse sabão, assim eu iria economizar bastante".

Colaboradora C: "Vamos ver se estou tendo prejuízo (risos). Sabe professor, depois que fiquei sozinha, nunca fiz as contas na ponta do lápis é tudo na base do "olhômetro", sabe?".

Colaboradora D: "P, quero muito fazer esta receita. Acho que poderia fazer sabão para lavar meu quintal e pano de chão, mas sinto muita dificuldade com números com vírgulas e com as medidas de xícaras, porque a minha xícara pode ser menor que a da minha vizinha e dar tudo errado (risos)". (FALAS DAS COLABORADORAS DO BC).

A partir dessas falas, é possível observar que elas perceberam que, seguindo a receita, conseguiriam sem muitas dificuldades realizar os procedimentos necessários, uma vez que suas experiências com os afazeres domésticos lhes dariam mais confiança no momento de produzir o sabão.

Um ponto importante a se destacar foi a clareza, para as participantes, de que a experiência da colaboradora $\mathrm{C}$ contribuiria para o andamento da oficina, pois a troca de experiências é um fator muito importante no processo de aprendizagem. Com isso, as próprias colaboradoras enxergaram que a utilidade da fabricação do sabão vai além do uso doméstico ou até mesmo da sua comercialização.

Perceberam também que, por mais entediantes que possam parecer, os cálculos que teriam que fazer no processo de precificação seriam fundamentais e que estes envolveriam conceitos de matemática básica, como ponto de partida para a superação das dificuldades.

Assim, o propósito das intervenções foi justamente evidenciar como a aplicação da matemática pode se dar de forma ampla e acessível, independentemente do nível de escolaridade, sempre as motivando-as e enfatizando que são capazes de atingir e concluir a meta proposta, uma vez que com o trabalho cooperativo é possível obter resultados positivos.

A fim de ilustrar os procedimentos adotados, segue abaixo uma situação-problema proposta: 
Após participar de um evento sobre a ES, Dona Marlene (nome fictício para a integrante deste empreendimento) percebeu que poderia ganhar dinheiro vendendo sabão produzido por ela mesma (e sem gastar muito), pois poderia coletar na comunidade o óleo doméstico usado. Animada, foi até o BC a fim de obter um empréstimo para iniciar o novo empreendimento. Assim que chegou foi informada que pagaria $1 \%$ de juros simples ao mês. No entanto, Dona Marlene passou por uma análise de crédito e lhe foram disponibilizados $\mathrm{R} \$ 500$ reais. Sem saber se as vendas do sabão seriam positivas, optou por pagar o empréstimo em 10 vezes. Dona Marlene solicitou que as colaboradoras do BC fizessem uma análise da viabilidade do seu empreendimento.

Tabela 1 - Itens para uma receita

\begin{tabular}{|cl|}
\hline \multicolumn{3}{|c|}{ Sabão líquido caseiro - Rende 25} \\
\hline$\checkmark$ & 02 Litros de óleo de cozinha usado \\
$\checkmark$ & 01 Litro de álcool combustível \\
$\checkmark$ & 1/2 Kg de soda cáustica \\
$\checkmark$ & 02 Litros de água fervente \\
$\checkmark$ & 14 Litros de água fria \\
$\checkmark$ & 14 Litros de água fervente \\
$\checkmark$ & 01 Tambor 30 Litros \\
\hline
\end{tabular}

Fonte: própria

Tabela 3 - Custo fixo

\begin{tabular}{|l|l|}
\hline Itens & Preço (R\$) \\
\hline Empréstimo & \\
\hline Aluguel & \\
\hline Depreciação & \\
\hline
\end{tabular}

Fonte: própria
Tabela 2 - Tabela de preços

\begin{tabular}{|l|l|}
\hline \multicolumn{1}{|c|}{ Produtos } & Preço (R\$) \\
\hline Óleo & - \\
\hline Álcool combustível & $\mathrm{R} \$ 3,10$ \\
\hline Água & $\mathrm{R} \$ 30,32$ \\
\hline Gás & $\mathrm{R} \$ 54,90$ \\
\hline Soda cáustica & $\mathrm{R} \$ 7,40$ \\
\hline Garrafa plástica 1L unidade & $\mathrm{R} \$ 0,40$ \\
\hline Galão 30L (2 anos) & $\mathrm{R} \$ 17,50$ \\
\hline Aluguel Salão & $\mathrm{R} \$ 250,00$ \\
\hline Gás & $\mathrm{R} \$ 54,90$ \\
\hline
\end{tabular}

Fonte: própria

Tabela 4 - Custo de produção

\begin{tabular}{|l|l|}
\hline \multicolumn{1}{|c|}{ Produtos } & \multicolumn{1}{c|}{ Preço (R\$) } \\
\hline Óleo & \\
\hline Álcool combustível & \\
\hline Água & \\
\hline Gás & \\
\hline Soda cáustica & \\
\hline Garrafa 1un & \\
\hline Custo final R\$ & \\
\hline
\end{tabular}

Fonte: própria 
Tabela 5 - Panorama geral

\begin{tabular}{|c|c|}
\hline Itens & Preço (R\$) \\
\hline Preço de venda & \\
\hline Custos Variáveis & \\
\hline Margem de & \\
contribuição & \\
\hline
\end{tabular}

Fonte: própria

Ajude Dona Marlene e suas colaboradoras a efetuar os cálculos que faltam nas tabelas acima a fim de analisar a situação do empréstimo. Considere que gasta-se $0,200 \mathrm{~kg} / \mathrm{h}$ de gás em temperatura baixa (forno abaixo de 180 graus com as 4 bocas) e 20 min para ferver 3,5 L de água.

Quadro 1 - Situação-problema focalizando análise de um empreendimento de produção de sabão.

O desenvolvimento desta atividade durou por volta de 3 horas. Primeiramente, foi feita a leitura da proposta e uma breve discussão a respeito disso e, em seguida, com o auxílio do pesquisador, buscou-se identificar o objetivo central da proposta. A partir disso, também em conjunto, foram identificados, como referências, empreendimentos parecidos e, na sequência, iniciou-se o processo de precificação.

O primeiro passo foi estruturar a ideia por escrito para que elas pudessem fazer os cálculos, passo a passo, com o acompanhamento do pesquisador. Como já mencionado, nem todas as colaboradoras possuem a mesma bagagem conceitual. Portanto, foi de suma importância que o processo de ensino e aprendizagem ocorresse de forma gradual. A colaboradora D teve um pouco mais dificuldade, mas aos poucos, conseguiu desenvolver por conta própria um algoritmo que a ajudasse na utilização do conceito de proporcionalidade por meio de uma regra de três.

No entanto, é importante destacar que antes de chegar à elaboração da regra de três, observou-se que elas conseguiram estabelecer conceitos de proporcionalidade mentalmente, por exemplo, perceberam que se $1 \mathrm{~kg}$ de farinha custa $\mathrm{R} \$ 5,00,1 / 2 \mathrm{~kg}$ custa $\mathrm{R} \$ 2,50$. Para elas esse modo de utilizar a matemática se tornou algo natural, pois vivenciam isso com frequência quando fazem compras. Então, a partir dessas percepções, os conceitos foram trabalhados gradativamente.

Esse cálculo mental ficou evidente na intervenção e foi generalizado em forma de regra de três. A partir do momento que os cálculos passaram a fazer sentido, as colaboradoras perceberam que a compreensão desses conceitos poderia ajudá-las em situações do dia a dia como, por exemplo, ao fazerem compras no mercado. Isso explicita claramente um dos princípios da Andragogia: ver sentido naquilo que fazem. 
De modo geral, elas conseguiram, sozinhas, encontrar o custo da produção final e a partir dele refletir sobre a formação de preço. Para tanto, foi preciso colocar "na ponta do lápis" cada cálculo feito, levando em consideração o valor de venda do produto, bem como o custo fixo e o custo variável, a fim de obter o chamado valor excedente (ou seja, o lucro na terminologia usual). Um fato observado a partir dessa análise foi que elas conseguiram transpor a aprendizagem desse conteúdo para outro empreendimento de produção de produto de limpeza, do qual participa também uma delas e com isso, elas perceberam que tinham prejuízo de um real ( $\mathrm{R} \$ 1)$ em um dos produtos desse EES.

Saber aplicar conhecimentos adquiridos em outras situações é um indicativo, segundo a teoria de Ausubel (1982), de que a aprendizagem foi significativa. Conceitos novos, como depreciação, margem de contribuição e ponto de equilíbrio eram até então desconhecidos e, com a intervenção, elas obtiveram uma compreensão sobre tais conceitos e passaram a empregá-los com mais naturalidade. Assim, elas notaram que a matemática financeira está presente em várias situações do cotidiano do $\mathrm{BC}$, porém com alguns termos técnicos, segundo a colaboradora A. Após o término dos cálculos, foi possível obter o valor unitário e, por fim, atribuir um preço de venda que considerassem justo.

\section{Segunda Fase: estudo da viabilidade de um novo EES de produção de pão caseiro}

Desenvolvemos empiricamente um estudo de viabilidade para um EES e, durante este desenvolvimento, passamos por algumas etapas do processo de elaboração do estudo de viabilidade, começando por: seleção de um empreendimento, análise de oferta e demanda, estudo de mercado e análise do processo de precificação. Pelo lado da oferta, observou-se que não havia empreendimentos semelhantes nas proximidades, a não ser algumas mulheres que vendiam pães em bairros mais afastados. Dessa forma, comparando a demanda e a oferta, constatou-se que existe uma necessidade do ponto de vista de mercado, pois a demanda é aparentemente maior do que a oferta.

Quanto à análise da demanda, o público escolhido para compra dos pães seria a comunidade universitária que é considerada um cliente em potencial. Para o caso do EES de fato existir, pontuou-se a necessidade de: mapeamento da região com as repúblicas universitárias, análise da demanda, estudo de possíveis pontos de entrega e, por fim, criação de uma rede entre empreendimentos de pães.

A partir do EES que as integrantes do BC sugeriram, utilizou-se a receita do pão caseiro fornecido por uma delas para estabelecermos o conceito de proporcionalidade para cada ingrediente para que fosse possível calcular o preço de cada unidade do produto. Vale ressaltar que a maioria dos integrantes do BC havia participado de oficinas pedagógicas de Educação Matemática antes e isso também foi considerado nessa situação. Numa breve 
conversa sobre dinheiro, juros e cartão de crédito, evidenciamos que no cotidiano lidamos com uma série de situações ligadas ao dinheiro, e que para melhor administrá-lo é muito importante saber como utilizá-lo.

Por isso, manter a Educação Matemática dentro de um BC é o mesmo que estabelecer um sistema de capacitação contínua. No entanto, para que a implementação da Educação Matemática fosse efetiva, seria fundamental que as oficinas ocorressem em um ambiente motivador. Afinal, a fim de desenvolver uma proposta de um empreendimento para angariar verbas para o BC, faz-se importante possibilitar a reflexão, o desenvolvimento da proatividade, do trabalho em grupo e da autonomia do conhecimento.

Após discutirmos como a matemática pode se comportar e aparecer em diversas ocasiões do nosso cotidiano iniciou-se o processo de precificação do pão caseiro. Para tal, houve uma reflexão em conjunto a respeito dos preços unitários dos produtos e o cálculo de outras quantidades por meio do conceito de proporcionalidade.Por fim, iniciou-se a oficina com um questionamento:

"Se um quilo de trigo custa $R \$ 2,70$, dois quilos custam...?”

O interessante sobre essa reflexão não seria apenas saber o valor, mas sim como as colaboradoras do BC pensaram para chegar ao resultado, a saber:

A: "Bom, é só eu pegar dois pacotes de trigo de 1kg. Daí eu somo R $2,70+$ $\mathrm{R} \$ 2,70 "$.

B: "Você quer o dobro, só multiplicar por 2!"

C: "Ia falar a mesma coisa que a colaboradora B"

D: "dois, somados com dois resulta em quatro, setenta somado com setenta, resultado em 140, só que nesse caso é 70 centavos, então é o mesmo que $\mathrm{R} \$ 1,40$. Então, quatro mais um e quarenta [pensando] $\mathrm{R} \$ 5,40$ !”. (FALAS DAS INTEGRANTES DO BC).

Após essa reflexão inicial o pesquisador colocou os elementos na lousa por meio da regra de três. Propositalmente, ele escreveu o seguinte: 2000 gramas referentes ao trigo na coluna do preço:

Ingredientes
10oo gramas ---------------------------2,70
$X$

Imediatamente a colaboradora A questionou:

A: "P, mas você não falou que sempre temos que olhar para o que estamos calculando? Unidade embaixo de unidade, preço embaixo de preço, ingrediente embaixo de ingrediente [...]".

P: "A, coloquei de propósito! Fico muito feliz que você conseguiu entender

[..]”. (FALA DA INTEGRANTE A DO BC E DO PESQUISADOR)

Essa situação deixa claro que as experiências anteriores por elas vivenciadas em Educação Matemática mostram-se eficientes, porque elas conseguiram utilizar o conceito de 
proporcionalidade para o cálculo solicitado, assim como compreenderam o modo dessa sistematização por meio da regra de três.

E assim foram feitos os demais cálculos para cada ingrediente da massa, para o custo final do fermento, para o custo proporcional do gás e para os itens da embalagem de vendas (etiquetas, saco transparente e fitinhas). Cada receita torna possível a confecção de oito pães de tamanho médio. Em todos esses casos, o uso de números decimais era inevitável, portanto, efetuou-se uma discussão a esse respeito, partindo de uma reflexão sobre uma situação do próprio cotidiano. Desse modo, levantou-se o seguinte questionamento: "Se estivessem em um mercado e precisassem calcular, mentalmente, o valor proporcional aproximado de certo produto como, por exemplo, a quantidade em gramas de um embutido, como fariam?”. A colaboradora C relatou que quando está sem o celular, ela arredonda os preços para cima e então sabe que pagará menos do que calculou.

B: "P, eu adoro queijo, então se eu vou comprar 250 gramas e o quilo custa $\mathrm{R} \$ 22,60$ eu já iria ficar perdida para fazer a conta (risos). Meu truque é imaginar que o quilo custa $\mathrm{R} \$ 23,00$ e como eu quero 250 gramas, é o mesmo que $1 / 4$, certo? Então eu divido 23 por 4 . Bom, daí eu penso na tabuada, qual número mais se aproxima do 23 . Vamos lá: $4 \times 1=4 ; 4 \times 2=8 ; 4 \times 3=12 ; 4 \times 4=$ 16; 4x5 = 20; 4x6 = 24. Pronto, como eu arredondei para cima e 4x6 é o que chegou mais próximo do meu valor, eu sei que vai dar bem menos que 6 reais e que eu vou receber troco. Meio maluco, mas sempre deu certo".

$\mathrm{P}:$ "B, [...] existem muitas maneiras de você aprender matemática e você simplesmente usou sua criatividade para lidar com um imprevisto. Nesse caso, não existe o certo ou o errado. É muito comum pessoas na faculdade fazerem esse tipo de aproximação que você fez". (FALAS DA INTEGRANTE B DO BC E DO PESQUISADOR).

Os relatos foram surpreendentes, pois mostram que a experiência e a compreensão dos conceitos permitem que o indivíduo desenvolva estratégias para lidar com as situações cotidianas em que são exigidos cálculos mentais.

Por fim, depois de muitas reflexões, o processo de precificação foi finalizado e chegou-se às respostas para as seguintes perguntas que foram apresentadas ao grupo.

Em primeiro lugar, apresentou-se ao grupo a questão: "Qual o custo final para fabricar um pão?”. Em relação a esta questão o grupo chegou ao valor de $\mathbf{R} \mathbf{\$}, \mathbf{8 3}$ embalado ou R\$ 1,57 somente o pão assado. Depois perguntou-se: "Qual valor sugerido para a venda?” Sobre isso, o grupo sugeriu o valor de $\mathbf{R} \$ \mathbf{5 , O o}$. Na sequência indagou-se: “Quantos pães se pretende vender em um mês?”. O grupo indicou 40 pães. Por fim, apresentou-se a seguinte pergunta: “Qual seria seu capital de giro?”. Para esta pergunta, o grupo indicou que seria menos de 50 reais.

Nesta etapa do trabalho em que se analisou a viabilidade de um novo EES, constatou-se que as vivências pedagógicas em Educação Matemática anteriores foram importantes e auxiliaram o grupo a resolver com maior prontidão essa nova situação. Com isso, foi possível trabalhar os conceitos matemáticos de uma forma mais ampla e 
considerando os diversos fatores importantes de serem analisados no caso de se propor um novo EES e, consequentemente, de se analisar um EES quando o mesmo solicita ao BC um empréstimo.

Assim, acreditamos que o estudo da viabilidade de um EES foi uma importante ferramenta que auxiliou as integrantes do $\mathrm{BC}$ nas tomadas de decisões e no gerenciamento de um empreendimento, fatores que também contribuem nas atividades do BC, ou seja, na análise de empreendimentos visando a concessão de empréstimo.

\section{Considerações finais}

No primeiro momento este trabalho visou identificar quais seriam as dificuldades das colaboradoras com assuntos da matemática a fim de desenvolver propostas relacionadas a empréstimos de empreendimentos como forma de auxiliá-las na compreensão e na aprendizagem dos conteúdos matemáticos envolvidos.

As intervenções apresentaram caráter satisfatório, observou-se que elas conseguiram efetuar análises de empreendimentos em relação a todo o processo de precificação e à questão de custo e benefício. Das quatro colaboradoras que participaram das atividades, a colaboradora que possui ensino médio regular completo, apresentou algumas dificuldades, mas conseguiu superar parte delas. A colaboradora $B$, que possui ensino médio EJA (Educação de Jovens e Adultos) completo, apresentou muitas dificuldades que alegou serem fruto do longo tempo que passou afastada da escola. A colaboradora $C$, que possui ensino médio regular completo, teve algumas dificuldades, porém foi a que mais se destacou por ter um domínio mais sólido de números decimais e fracionários. Por fim, a colaboradora $D$, com ensino fundamental incompleto, foi a que apresentou maior dificuldade, porém foi a mais esforçada e a que mostrou uma evolução mais significativa.

O fato é que, durante as intervenções, foram consideradas as individualidades de cada membro do grupo e a integração entre elas foi incentivada. Esse foi um aspecto importante para se criar um ambiente motivador à aprendizagem dos conhecimentos em questão.

O propósito essencial das intervenções foi abordar conhecimentos matemáticos e gerais que contribuíssem para a autonomia, autoconfiança, poder de decisão e habilidades diversas das integrantes do BC. A autonomia e a independência são fundamentais na aprendizagem e, por isso, após várias intervenções, surgiu a necessidade de que as próprias colaboradoras direcionassem os assuntos a serem trabalhados, pois não há desenvolvimento da autonomia num ambiente em que prevaleça o autoritarismo, no qual somente o educador tome decisões sem a participação das integrantes do BC.

Assim, destacamos que, do ponto de vista da ES, o desenvolvimento da autonomia e da independência na resolução de problemas e nas tomadas de decisões fortalecem o banco 
para que o mesmo seja solidificado como um EES. Acreditamos que por meio de uma relação de respeito e confiança construída ao longo do tempo, o processo de ensino e aprendizagem se intensifica na formação de indivíduos autônomos. Foi possível observar, que por meio da troca de informações e experiências, as próprias integrantes do BC criaram mais intimidade e se sentiram mais livres para buscar soluções e apresentar novas ideias para o grupo.

Consideramos, portanto, ser de fato muito efetivo para a aprendizagem, que atividades deste tipo sejam realizadas de forma cooperativa, em grupo e respeitando a individualidade de cada um; fatores já destacados como importantes no referencial teórico adotado. Neste caso, sugere-se que o educador atue mais como facilitador e deixe que os próprios sujeitos construam os conhecimentos de que necessitam, sendo auxiliados quando solicitarem.

Além disso, salientamos que, com base nos princípios da Etnomatemática, buscouse trabalhar os conteúdos matemáticos de forma contextualizada à realidade do $\mathrm{BC}$ e isso também contribuiu muito para a compreensão dos conceitos envolvidos e para o desenvolvimento de uma maior autonomia nas atividades do banco. Esse fato pode vir a refletir positivamente na comunidade, pois a missão do BC é promover o desenvolvimento local através da organização e mobilização populares acerca de questões sociais, políticas e econômicas específicas de cada território, assim como de sua relação com o todo, ou seja, com a cidade da qual fazem parte.

Desse modo, entendemos que a Educação Matemática na forma como foi empregada pode alcançar e contribuir para o desenvolvimento do sujeito como um ser social, permitindo a transformação e a construção de uma nova realidade. Em particular para o caso do BC, as ações que se iniciam dentro do Banco se refletem positivamente na comunidade.

Levando em consideração que os aprendizes adultos são conscientes e possuem uma vasta experiência de vida, notou-se que eles precisam ver utilidade no que estão fazendo para que o ensino e a aprendizagem ocorram de forma significativa.

Assim, este trabalho reforça nossa percepção de que a Educação Matemática pode auxiliar o sujeito na transformação e na construção de uma nova realidade tanto no âmbito do trabalho quanto da vida em comunidade.

\section{Referências}

AlbuQUerque, P. P. de. Autogestão. In: CATTANI, A. D. (Org.). A outra economia. Porto Alegre: Veraz, 2003. p. 20-26.

AUSUBEL, D. P. A aprendizagem significativa: a teoria de David Ausubel. São Paulo: Moraes, 1982.

CAVALCANTI, R. de C.; GAYO, M. A. F. da S. Andragogia na educação universitária. Revista Conceitos, João Pessoa, n. 11 e 12, p. 44-51, jul. 2004/jul. 2005. Disponível em: 
http://www.wr3ead.com.br/UNICEAD/andragogia_na_educacao_universitaria.pdf. Acesso em 17 jun. 2016.

D’AMBrosiO, U. Educação Matemática: da teoria à prática. Campinas: Papirus, 1996. Etnomatemática: elo entre as tradições e a modernidade. Minas Gerais: Autêntica, 2001.

. Etnometodologia, etnomatemática, transdisciplinaridade: embasamentos críticofilosóficos comuns e tendências atuais. Revista Pesquisa Qualitativa, São Paulo, v. 1, n. 1, p. 155-167, 2005.

LÜDKE, M.; ANDRÉ, M. E. D. A. Pesquisa em educação: abordagens qualitativas. São Paulo: EPU, 1986.

MENEGHETTI, R. C. G. A Teoria da Auto-organização, a Economia Solidária e a Etnomatemática: a aprendizagem como fator comum. Acta Scientiae, Canoas/RS, v. 15, n. 3, p. 535-550, set./dez. 2013.

MENEGHETTI, R. C. G.; BARROFALDI, R. C. Z. Práticas Efetivas de Educação Matemática no contexto de um banco comunitário. BOLEMA: Boletim de Educação Matemática, Rio Claro, v. 29, n. 53, p. 809-827, dez. 2015.

MENEGHETTI, R. C. G.; KUCINSKAS, R. A dicotomia matemática em uma marcenaria coletiva feminina: Matemática Escolar versus Matemática do Trabalho. In: TEIXEIRA, Manoel L. C. (Org.). Educação Matemática: intersecções. Verlag, Alemanha: Novas Edições Acadêmicas, 2014. p. 81-96.

MOREIRA, D. Etnomatemática e mediação de saberes matemáticos na sociedade global e multicultural. In: FANTINATO, M. C. C. B. (Org.). Etnomatemática: novos desafios teóricos e pedagógicos. Niterói: Editora da Universidade Federal Fluminense, 2009. p. 59-68.

OGLIARI, L. N. A Matemática no Cotidiano e na Sociedade: Perspectivas do Aluno de Ensino Médio. p.1-15. Disponível em: http://www.portalgeobrasil.org/colab/artigos/matematicacotidiano.pdf. Acesso em 15 jul. 2016.

SHINODA, A. C. M. et al. Um estudo sobre a utilização de andragogia no ensino de pósgraduação em administração. REGE, São Paulo, v. 21, n. 4, p. 507-523, out./dez. 2014.

SINGER, P. A economia solidaria no Brasil: a autogestão como resposta do desemprego. São Paulo: Contexto, 2000.

Introdução a Economia Solidária. São Paulo: Fundação Perseu Abramo, 2002. 
. Economia Solidária: entrevista com Paul Singer. Economia Solidária. Revista

Estudos Avançados, São Paulo, v. 22, n. 62, p. 289-314, jan.-abr. 2008. Entrevista concedida a Paul Israel Singer.

\section{Agradecimentos}

Os autores agradecem aos membros do Banco Comunitário, pelo acolhimento e participação; aos pesquisadores parceiros do NUMIES, à concessão da bolsa pela Próreitoria de Graduação da Universidade de São Paulo (Programa Unificado de Bolsas de Estudos - Pesquisa); ao MEC: Proext/2015 (Ministério da Educação: Programa Extensão Universitária/2015). Projeto aprovado: Ações pedagógicas em Educação Matemática para membros de Empreendimentos de Economia Solidária da cidade de São Carlos/SP.

\section{Biografia Resumida}

Renata Cristina GeromelMeneghetti - Licenciada em Matemática pela Universidade Estadual Paulista "Júlio de Mesquita Filho" (UNESP/Rio Claro). Mestre e Doutora em Educação Matemática pela Universidade Estadual Paulista "Júlio de Mesquita Filho" (UNESP/Rio Claro). Pós-doutorado pelo Centro de Lógica e Epistemologia e História da Ciência (CLE) da Universidade Estadual de Campinas (UNICAMP). Professora Associada da Universidade de São Paulo (USP), São Carlos, São Paulo, Brasil. Professora Colaboradora junto ao Programa de Pós-graduação em Educação para Ciências (UNESP/Bauru). Líder do Grupo de Pesquisa em Educação Matemática e Economia Solidária.

Email: rcgm@icmc.usp.br.

Link do Lattes:http://lattes.cnpq.br/8922871845300995

Douglas Felipe Giaquinto - Graduando do curso de Estatística pelo Instituto de Ciências Exatas e de Computação da Universidade de São Paulo e orientando da professora Renata Cristina GeromelMeneghetti em projeto de iniciação científica. Membro do Grupo de Pesquisa em Educação Matemática e Economia Solidária.

Email: douglas.giaquinto@gmail.com.

Link do Lattes: http://lattes.cnpq.br/5391376476311310 